\title{
Radiation Shielding Effect of Boron Carbide Aluminum Metal Matrix Composite
}

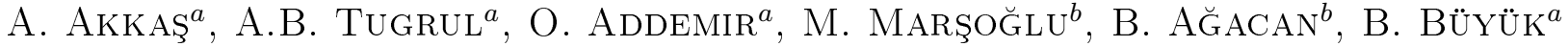 \\ ${ }^{a}$ Istanbul Technical University, Energy Institute, Nuclear Researches Division, \\ ITU Ayazaga Campus, 34469, Sariyer, Istanbul, Turkey \\ ${ }^{b}$ Yıldız Technical University, Metallurgical and Materials Engineering, 34210, Istanbul, Turkey
}

\begin{abstract}
Boralyn $\left(\mathrm{Al} / \mathrm{B}_{4} \mathrm{C}\right)$ composite material is produced chiefly of boron carbide and aluminum. Boron Carbide is an important material for the nuclear industry due to high neutron absorption cross-section. This composite is used as shielding materials to absorb neutrons in the nuclear reactors and control road materials. In this study we investigated $\mathrm{Al} / \mathrm{B}_{4} \mathrm{C}$ composites against gamma radiation. For that purpose, 5 wt.\%, 10 wt.\%, 15 wt.\% and 20 wt.\% reinforcement content were investigated. Cs-137 gamma radioisotope source which has $662 \mathrm{keV}$ gamma energy photons were used. For each material, linear and mass attenuation coefficients were calculated. Theoretical mass attenuation coefficients were calculated from XCOM computer code. The theoretical results were compared with experimental results. The results were showed that increasing the amount of Boron Carbide compound content of boralyn composite material decrease the linear and mass attenuation coefficient of materials
\end{abstract}

DOI: 10.12693/APhysPolA.127.947

PACS: 25.20.Dc

\section{Introduction}

Radiation shielding involves placing a shielding material between the ionizing radiation source and the worker or the environment [1]. There are several factors that influence the selection and use of radioactive shielding materials. Considerations such as attenuation effectiveness, strength, resistance to damage, thermal properties, and cost efficiency can affect radiation protection in various ways [2].

Boron Carbide $\left(\mathrm{B}_{4} \mathrm{C}\right)$ is a very hard $(9.5+$ in Mohs scale), low specific gravity (2.52), covalent ceramic that offers distinct advantages for applications involving neutron absorption, wear resistance, and impact resistance. The extreme sensitivity of $\mathrm{B}_{4} \mathrm{C}$ to brittle fracture $\left(\mathrm{K}_{l c}=3.7 \mathrm{MPa} \mathrm{m}^{1 / 2}\right)$ and the difficulties associated with fabricating fully dense microstructures are seriously limiting its use [3]. By using certain additives (e.g. graphite or aluminum), it is more suitable for production or manufacturing.

Aluminum alloys are still the subjects of intense studies, as their low density gives additional advantages in several applications. These alloys have started to replace cast iron and bronze in wear resistance parts manufacture [4]. Aluminum reinforced Boron Carbide composite has interesting features such as high strength and high hardness [5]. These characteristics have made this composite as a very perspective material in the field of engineering. The usage of Aluminum reinforced with Boron Carbide composite become especially perspective in protection from neutron radiation application due to its ability

corresponding author; e-mail: akkasayhan@hotmail.com to absorb neutrons very well. This composite is used as shielding materials to absorb free neutrons coming from the reaction in the nuclear reactor and to avoid any radiation escape to the surrounding environment [6]. Boron Carbide is a material with higher hardness than aluminum with the reading of 2.75 Mohs compared to 9.3 Mohs. Thus, the increase in the quantity of Boron Carbide in the composites increases the hardness of the $\mathrm{Al} / \mathrm{B}_{4} \mathrm{C}$ composites [7].

Berger and Hubbell developed the XCOM computer software for calculating cross-section and attenuation coefficient for elements, compounds and mixtures for photon energies from $1 \mathrm{keV}$ to $100 \mathrm{keV}$ [8].

In this study, we investigated the efficiency of Aluminum-Boron Carbide metal matrix composite material against the $\mathrm{Cs}-137$ radioisotope with gamma ray energy $662 \mathrm{keV}$. Results compared with XCOM software database.

\section{Experiments and materials}

The objective of the proposed work was to apply gamma-ray transmission method for studying the properties of Boron Carbide-aluminum metal matrix composites. Cs-137 gamma radioisotope source was used as gamma emitter in the experiments due to its monochromatic energy at $0.667 \mathrm{MeV}$.

Gamma ray transmission technique based on measuring the attenuation of photons of an incident radiation beam absorbed while passing through the materials. NaI scintillation detector is used for detection of gamma photons coming from radioactive $\mathrm{Cs}-137$ source. Materials are placed between source and the detector as shown in Fig. 1. Attenuation coefficient is determined for a given material by interposing increasing thickness of materials. Special precautions are taken to reduce amount of scattered photons which are detected by detector. For that, source collimator and detector collimator are used. 


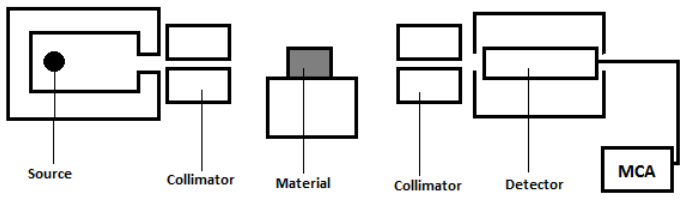

Fig. 1. Schematic view of gamma transmission technique.

The Beer's law establishes the relationship between the attenuated radiation intensity by a sample and other parameters of the system. It can be written as

$$
I=I_{0} \exp (-\mu x)
$$

where $I_{0}$ is incident gamma ray beam intensity (cont/s), $I$ is emergent gamma ray beam intensity (cont/s), $\mu$ is the linear attenuation coefficient of the sample $\left(\mathrm{cm}^{-1}\right)$ and $x$ is the thickness of the sample $(\mathrm{cm})$.

The mass attenuation coefficient $\mu_{m}$ can be written as

$$
\mu_{m}=\mu / \rho,
$$

where $\mu$ is the mass attenuation coefficient $\left(\mathrm{cm}^{2} / \mathrm{g}\right)$, and $\rho$ is the density of the sample $\left(\mathrm{g} / \mathrm{cm}^{3}\right)$.

With increase in sample thickness and collimator size (half acceptance angle) larger number scattered photons are generated, so the detector is exposed to higher scattered radiation [9]. To minimize this effect, detector was placed $50 \mathrm{~cm}$ away from gamma source. Lead blocks were used for radiation shielding and collimating of gamma rays. The collimator has a $3 \mathrm{~mm}$ diameter hole. The scattering effect was minimized by using thin hole collimator.

After background radiation was measured, gamma intensity was measured without any material $\left(I_{0}\right)$. Finally for all materials, gamma intensities were measured at different thicknesses $(I)$. Net intensity counts were calculated by subtracting background. To achieve rational evaluation, relative intensity $\left(I / I_{0}\right)$ values were calculated for the composite materials at different thickness. Then relative intensity-material thickness graphs were drawn.

Boron Carbide reinforced aluminum composites possess an unique combination of high specific strength, high elastic modulus, good wear resistance and good thermal stability than the corresponding non-reinforced matrix alloy system.

Boron Carbide-Aluminum metal matrix composites were used in experiment. Materials have different Boron Carbide contents, 5\%, 10\%, $15 \%$ and 20\%. Composite materials were produced by cold pressing method at 540 under $2 \mathrm{MPa}$ pressure for 3 minute. Contents of the studied composite materials and their properties are given in Table I.

\section{Results and discussion}

The experimental work consists of two steps. In the first step, material thicknesses were measured. In the
Content of the studied composite materials and their properties.

TABLE I

\begin{tabular}{c|c|c|c|c}
\hline $\begin{array}{c}\text { Material } \\
\text { Code }\end{array}$ & $\begin{array}{c}\mathrm{B}_{4} \mathrm{C} \\
(\% \mathrm{Vol})\end{array}$ & $\begin{array}{c}\mathrm{Al} \\
(\% \mathrm{Vol})\end{array}$ & $\begin{array}{c}\text { Density } \\
\left(\mathrm{g} / \mathrm{cm}^{3}\right)\end{array}$ & $\begin{array}{c}\text { Standart Deviation } \\
\left(\mathrm{g} / \mathrm{cm}^{3}\right)\end{array}$ \\
\hline $\mathrm{A} 01$ & 5 & 95 & 2.638 & 0.011 \\
\hline $\mathrm{A} 02$ & 10 & 90 & 2.606 & 0.012 \\
\hline $\mathrm{A} 03$ & 15 & 85 & 2.563 & 0.045 \\
\hline $\mathrm{A} 04$ & 20 & 80 & 2.526 & 0.087 \\
\hline
\end{tabular}

second step, for the different material thickness, gamma photons which pass through from materials were counted. The results of experiments are given in Fig. 2 as relative intensity-thickness graphs for A01, A02, A03 and A04 against $\mathrm{Cs}-137$ radioisotope.

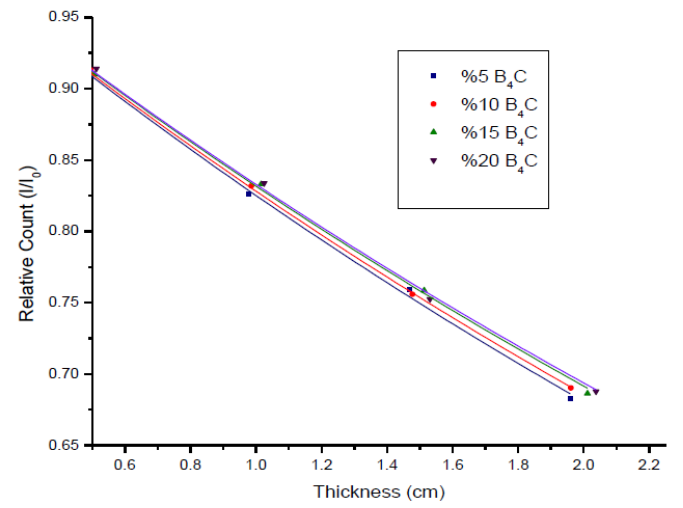

Fig. 2. Relative Intensity-Thickness Graph for A01, A02, A03 and A04 against Cs-137 radioisotopes.

Total attenuation of the composite materials versus energy of gamma ray is calculated with XCOM computer software and Fig. 3 shows the results of the calculations.

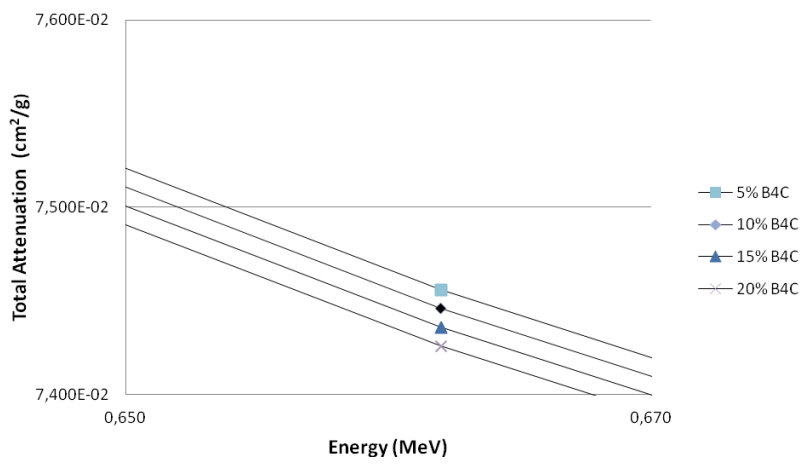

Fig. 3. Total attenuation of materials versus energy of gamma ray is calculated with XCOM computer program.

From the experiment results, linear and mass attenuation coefficients are calculated. Linear attenuation coefficient values and mass attenuation coefficient values are decreasing with increasing of the percentage of Boron 
Carbide compound of composite materials as it can be seen from Fig. 2 and Table II.

Linear attenuation coefficients for the composite materials

TABLE II

\begin{tabular}{c|c|c}
\hline \hline $\begin{array}{c}\text { Material } \\
\text { code }\end{array}$ & $\begin{array}{c}\text { Linear attenuation } \\
\text { coefficient, } \mu\left(\mathrm{cm}^{-1}\right)\end{array}$ & $\begin{array}{c}\text { Mass attenuation } \\
\text { Coefficient, } \mu / \rho\left(\mathrm{cm}^{2} / \mathrm{g}\right)\end{array}$ \\
\hline $\mathrm{A} 01$ & $0.1919 \pm 0.0035$ & $0.07274 \pm 0.0013$ \\
\hline $\mathrm{A} 02$ & $0.1874 \pm 0.0025$ & $0.07191 \pm 0.0010$ \\
\hline $\mathrm{A} 03$ & $0.1839 \pm 0.0033$ & $0.07175 \pm 0.0012$ \\
\hline $\mathrm{A} 04$ & $0.1805 \pm 0.0050$ & $0.07146 \pm 0.0019$
\end{tabular}

The theoretical mass attenuation coefficients were calculated from XCOM software code and the Windows version of WinXCom. The computation of mass attenuation and mass energy-absorption coefficients for 290 elements, compounds and mixtures could be calculated successfully. The program limits the choice of the constituents (element, compound or mixture) in the absorber material to a maximum of six [10]. It could used for the calculation of mass attenuation coefficients of different composed materials effectively [11-14].

The difference in percentages between theoretical and experimental values were calculated. Experimental, theoretical mass attenuation coefficients and their difference percentages are given in Table III. It can be seen that theoretical mass attenuation coefficients are higher than the experimental mass attenuation coefficients [15]. The percentage differences between theoretical and practical experiment results are below $4 \%$. However, differences are acceptable because of XCOM takes the materials to be pure, but the materials have some impurity in practice.

Experimental and mass attenuation coefficients of the composite materials

TABLE III

\begin{tabular}{c|c|c|c}
\hline \hline \multirow{2}{*}{$\begin{array}{c}\text { Material } \\
\text { code }\end{array}$} & \multicolumn{3}{|c}{ Mass attenuation coefficient $\mu / \rho\left(10^{-2} \mathrm{~cm}^{2} / \mathrm{g}\right)$} \\
\cline { 2 - 4 } & Experimental & $\begin{array}{c}\text { Theoretical } \\
(\mathrm{XCOM})\end{array}$ & Difference [\%] \\
\hline A01 & 0.07274 & 0.07456 & 2.4 \\
\hline A02 & 0.07191 & 0.07446 & 3.4 \\
\hline A03 & 0.07175 & 0.07436 & 3.5 \\
\hline A04 & 0.07146 & 0.07426 & 3.8 \\
\hline
\end{tabular}

\section{Conclusion}

Aluminum-Boron Carbide Metal Matrix Composite Materials are investigated against Cs-137 gamma radioisotope source. Materials with different amount of Boron Carbide content are used for experiment. As a result, increase the amount of Boron Carbide powder in materials give rise to decrease of the linear and mass attenuation coefficients of composite material. The theoretical and experimental results are compatible with each other. Therefore, it can be said that the calculated results also agree with the experimental results.

\section{Acknowledgments}

We are grateful to the Cekmece Nuclear Research and Training Center for their support to this study.

\section{References}

[1] Y. Elmahroug, B. Tellili, C. Souga, International Journal of Physics and Research (IJPR) 3, 33 (2013).

[2] H. Hu, Q. Wang, J. Qin, IEEE Transactions on Nuclear Science 55, (2008).

[3] D.C. Halverson, A.J. Pyzik, I.A. Aksay, W.E. Snowden, J. Am. Ceram. Soc. 72, 775 (1989).

[4] U.B. Gopal Krishna, K.V. Sreenivas Rao, B. Vasudeva, Int. Journal of Metallurgical \&s Materials Science and Engineering (IJMMSE) 3(1), 41 (2013).

[5] Y. Abdullah, M.R. Yusof, A. Muhammad, N. Kamarudin, W.S. Paulus, R. Shamsudin, N.H. Shudin, N.M. Zali, Journal of Nuclear and Related Technologies $\mathbf{9}$ (1) (2012).

[6] F. Toptan, A. Kilicarslan, I. Kertil, Materials Science Forum 636, 192 (2010).

[7] P. Zhang, Y. Li, W. Wang, Z. Gao, B. Wang, Journal of Nuclear materials 437, 350 (2013).

[8] M.J. Berger, J.H. Hubbell, XCOM: Photon Cross sections on a personal computer" web version 1.2, (1999) http://www.nist.gov/pml/data/xcom/.

[9] G.S. Sidhu, K. Singh, P.S. Singh, G.S. Mudahar, Indian Academy of Sciences 53, 851 (1999).

[10] L. Gerward L, N. Guilbert, K. Bjorn, H. Levring, Radiation Phys Chem. 60, 23 (2001).

[11] B. Buyuk, A.B. Tugrul, A.C. Akarsu, A.O. Addemir, Acta Physica Polonica A 121, 135 (2012).

[12] B. Buyuk, A.B. Tugrul, A.C. Akarsu, A.O. Addemir, Journal of Nanomaterials: Applications and Properties (NAP-2011) 2, 381 (2011).

[13] B. Buyuk, A.B. Tugrul, S. Aktop, A.O. Addemir, Acta Physica Polonica A 123, 177 (2013).

[14] B. Buyuk, A.B. Tugrul, Radiation Physics and Chemistry 97, 354 (2014).

[15] A. Akkas, PhD Thesis, Energy Institute - Istanbul Technical University, (in progress). 